\title{
An Amperometric Glucose Biosensor Based on
} electrostatic force induced Layer-by-layer \section{GOD/Chitosan/Pyrite on a Glassy Carbon Electrode}

Tingting $\mathrm{Ma}^{1,2}$, Yue Wang ${ }^{1, *}$, Ying $\mathrm{Hou}^{2}$, Enlei Wang ${ }^{2}$, Guoqing Yin ${ }^{1}$, Yasushi Hasebe ${ }^{3}$, Zhiqiang Zhang ${ }^{1, *}$

${ }^{1}$ School of Chemical Engineering, University of Science and Technology Liaoning, 185 Qianshan Middle Road, High-tech zone, Anshan 114051 Liaoning, China

${ }^{2}$ School of Mineral Engineering, University of Science and Technology Liaoning, 185 Qianshan Middle Road, High-tech zone, Anshan 114051 Liaoning, China

${ }^{3}$ Department of Life Science and Green Chemistry, Faculty of Engineering, Saitama Institute of Technology, 1690 Fusaiji, Fukaya, Saitama 369-0293, Japan

Corresponding author1: wangyue@ustl.edu.cn (Y. Wang)

Corresponding author2: zhangzhiqiang@ustl.edu.cn (Z. Zhang) 


\begin{abstract}
Pyrite (PR), as a representative sulfide mineral, possesses the advantages of abundant, thermodynamically stable, non-toxicity and semi-conductivity. In this study, an amperometric glucose biosensor (GOD/CS/PR/GCE) based on layer-by-layer of glucose oxidase (GOD), chitosan (CS) and pyrite (PR) on glassy carbon electrode (GCE) was fabricated through electrostatic force. In this research, PR suspension prepared in phosphate buffer ( $\mathrm{pH} 5.5$ ) was first immobilized on the GCE surface, which exhibits negative charge. Then, positively charged CS was adsorbed on PR/GCE by electrostatic force. Finally, negatively charged GOD was further modified on the CS/PR/GCE surface through electrostatic force again. The surface morphology and adsorbed mechanism were supported by field emission scanning electron microscopy (SEM), quartz crystal microbalance with dissipation (QCMD) and atomic force microscope (AFM). The step-by-step procedure gives both a strong adhesion ability and a good bioelectrocatalytic activity of GOD on the CS and PR modified electrode surface. The linear range of this GOD/CS/PR/GCE biosensor was achieved from $0.5 \mathrm{mM}$ to $60 \mathrm{mM}$ with the Linear regression equation of $\mathrm{y}=0.897 \mathrm{x}-0.3016\left(\mathrm{R}^{2}\right.$ $=0.9996$ ) and a limit of detection (LOD) value of $50 \mu \mathrm{M}$. This approach of using pyrite and chitosan as physical modified GOD to serve as electrostatic glues, which could be useful for designing better enzyme based biosensors for a wide variety of practical applications.
\end{abstract}

Keywords: Pyrite; Chitosan; Glucose oxidase; Glucose biosensor; Glassy carbon electrode; layer-by-layer modification 


\section{Introduction}

Glucose plays an important role in energy replenishment, liver detoxification and memory enhancement in organisms. Abnormal blood glucose levels can result in diseases like diabetes, cardiopathy, nephropathy, hypoglycemia, stroke or cardiovascular disorders. Diabetes is one of the biggest threats to human health globally and the number of diabetic patients increases year by year [1-3]. In addition, glucose is extensively used in various fields such as confectionery manufacturing, food processing, clinical and wine industry, etc. $[4,5]$. Therefore, the sensitive and accurate detection of glucose concentration is of great significance for the monitoring and treatment of related diseases and the control of industrial processes.

Compared with traditional analytical methods, for instance, spectrophotometry [6], fluorescence [7], titrimetry [8], high-performance and liquid chromatography (HPLC) [9], electrochemical biosensors have attracted great attention for their high sensitivity, excellent selectivity, low cost, eco-friendly, and fast detection speed [10-13]. Enzymes are promising green catalysts in the field of pharmaceutical intermediates, drugs and fine chemicals due to their renewability, earth-abundant and low cost properties [14]. Lots of functional materials were used in enzyme biosensors, including polymer [15], noble metal nanomaterials [16], graphene [17, 18], sol-gel [19], ionic liquid [20], ceramic matrix [21, 22], and sulfide mineral [23-27]. Pyrite (PR), as the most abundant sulfide ore in the earth, with the molecular formula of $\mathrm{FeS}_{2}$, is a $\mathrm{Fe}$ (II) polysulfide based cubic NaCl-type crystalline structure. It has been used as a cathode material for thermal batteries due to its excellent properties such as suitable redox electromotive force, high thermodynamic stability, suitable conductivity, and a fixed platform that can be charged and discharged [28]. Owing to the excellent electrochemical performance and the ability to transfer heterogeneous electrons, it has been studied extensively in electrochemical catalysis and sensing [29-31].

Glucose oxidase (GOD, $\beta$ - $D$-glucose) is a typical oxidoreductase and has been extensively applied in enzyme biosensors for the quantitative detection of glucose in both clinical diagnostics and food industry analysis [32]. It uses molecular oxygen as an electron acceptor to catalyze the oxidation of $\beta$-D-glucose to $\delta$-gluconolactone, which then hydrolyzes into gluconic acid and hydrogen peroxide spontaneously [33]. 
Usually, the use of enzymes outside the biological environments has challenge limitations including high cost, sensitive to surroundings, and narrow specificity, etc. The methods for immobilization of GOD on electrodes include physical adsorption [34, 35], covalent bonding, cross-linking [36-38], and entrapment in gels [39-41]. Each of these immobilization methods has their own advantages and disadvantages. Among them, physical adsorption is one of the simplest methods, which arouse great attentions in fabricating biosensors.

Chitosan (CS, $(1 \rightarrow 4)-\beta$ - $D$-glucosamine) is a kind of abundant natural polymer that derived from chitin and widely exists in the polysaccharides of insects, arthropods and crustaceans. CS has the advantages of low cost, high mechanical strength, chemical inertia, good hydrophilicity and strong film forming ability. This special polymer has important applications in the field of electroanalytical chemistry due to its nontoxicity and good biocompatibility $[42,43]$.

In this study, an amperometric glucose biosensor was constructed through layer-by-layer (LbL) physical adsorption of pyrite, CS and GOD on glassy carbon electrode (GCE) by using electrostatic force. LbL technique is a widely used adsorption method of a charged protein and oppositely charged species through electrostatic interactions [44]. It is an effective approach for enzyme immobilization due to its simplicity and mild operate condition. The LbL method is suitable for immobilizing different enzyme architectures with low denaturation effects because most enzymes are water-soluble and charged in solution phase [45]. Chitosan is a cationic polymer and has been the most widely employed for electroanalytical purposes [46]. The negatively charged PR/positively charged CS/negatively charged GOD-based structure of this biosensor is useful to keep both the bioelectrocatalytic activity and stability of adsorbed GOD due to strong electrostatic interaction. The adsorbed GOD exhibited adequate mediated response current toward glucose. In addition, the hydration layer of CS promotes the retention of GOD structure and activity to a significant extent [47]. Chitosan and pyrite worked as suitable protein glues, which bind to both the GOD and the GCE surface. These data suggested that raw pyrite could also be used directly as glucose oxidase based mediated electrochemical sensor after carefully design. 


\section{Experimental}

\section{Reagents and materials}

Glucose oxidase (GOD, EC 1.1.3.4 from Aspergillus niger; >100 units $\mathrm{mg}^{-1}$ ) was purchased from Sigma-Aldrich Co., China. Glucose, Chitosan (CS), hydroquinone (HQ), Ferrocene (FC), dopamine (DA), catechol (CC), $\mathrm{KH}_{2} \mathrm{PO}_{4}$ and $\mathrm{K}_{2} \mathrm{HPO}_{4}$ were obtained from Sinopharm Chemical Reagent Co., Ltd (China). A 0.1 M phosphate buffer (prepared by using $\mathrm{KH}_{2} \mathrm{PO}_{4}$ and $\mathrm{K}_{2} \mathrm{HPO}_{4}$ ) was used to prepare the electrolyte. Ferrous disulfide $\left(\mathrm{FeS}_{2}\right)$ was obtained from Tongling Weight Mineral Products Sales Co., Ltd. Pyrite (PR) was achieved from Yichun Luming Mining Co., Ltd. (Yichun, China). Pure $\mathrm{FeS}_{2}$ chips for QCM-D were purchased from Bai 'olin (Shanghai) Trading Co., Ltd. All reagents were used without further purification.

\section{Apparatus}

The morphology of the modified electrode was observed by use of field emission scanning electron microscope (FE-SEM) (SIGMA-HD, ZEISS). The phase and composition of pyrite were obtained by X-ray diffraction (D8 Advance, Bruker). The fabricated process was characterized by quartz crystal microbalance (QCM-D) and atomic force microscope (AFM). Electrochemical measurements were performed with a CHI 750D workstation (Shanghai Chenhua, China). A traditional three electrode system was used with modified pyrite electrode as working electrode, $\mathrm{Ag} / \mathrm{AgCl}$ (sat. $\mathrm{KCl})$ as reference electrode and Pt wire as counter electrode. All experiments were conducted at room temperature approximately $20^{\circ} \mathrm{C}$.

\section{Preparation of the GOD/CS/PR/GCE biosensor}

A glassy carbon electrode was polished with $1.0 \mu \mathrm{m}$ and $0.05 \mu \mathrm{m}$ of $\alpha$-alumina slurries powder, respectively. The GCE was sonicated with deionized water to remove adhered alumina and any impurities. Then, $30 \mathrm{mg} / \mathrm{mL}$ of PR suspension $(10 \mu \mathrm{L})$ was 
dropped on the cleaned GCE surface and allow to dry in air. Next, a chitosan (0.05\%) aqueous solution was dropped on the PR/GCE surface and continue to dry naturally. Finally, GOD (2 mg/mL) solution was casted on the CS/PR/GCE surface to prepare the biosensor (GOD/CS/PR/GCE). The preparation process is shown in Fig. 1.

\section{Results and discussion}

\section{Characterization of pyrite and pyrite based biosensor}

The phase characteristics of $\mathrm{FeS}_{2}$ and natural pyrite was examined by $\mathrm{X}$-ray diffraction (XRD) in Fig. 2. The composites contents were calculated and listed in Table 1. It can be seen that the contents of $\mathrm{FeS}_{2}$ in natural pyrite and pure $\mathrm{FeS}_{2}$ were $78.8 \%$ and $99.5 \%$, respectively. The main impurities of natural pyrite are $\mathrm{ZnS}$ and $\mathrm{SiO}_{2}$, respectively. In addition, the cyclic voltammetry (CV) methods were used to evaluate the performances of GOD/CS/PR/GCE and GOD/CS/FeS $/$ GCE, which prepared in the same way. The response peak current of GOD/CS/FeS $2 / G C E$ to glucose was $35 \%$ higher than that of GOD/CS/PR/GCE (data not shown). Hence, we think the purity of mineral is important to get better current response.

The structures and morphologies of PR/GCE (A), GOD/PR/GCE (B), CS/PR/GCE (C) and GOD/CS/PR/GCE (D) were characterized by FE-SEM. Fig. 3a shows that the raw pyrite is in a bulky shape. The edges of PR are clearly observed and the GOD layer seems thin on the PR surface in Fig. 3b. Hence, we speculated that GOD cannot cover the PR surface completely when it was directly adsorbed on the PR modified GCE as shown in Fig. 3b. In comparison to Fig. 3b, the granular and rounded morphology was observed in Fig. 3c. This attributed to the strong film forming ability of CS. Fig. 3d shows a thick and film-like layer of GOD on the CS/PR/GCE electrode surface. To identify our speculation, we measured the XRD in different cases including PR, GCE, CS, GOD, CS/GCE, PR/GCE, CS/PR/GCE and GOD/CS/PR/GCE, respectively. Without CS modification, the sharp peaks of PR were observed clearly even on GOD/PR/GCE surface (data not shown). However, in the presence of CS, the sharp peaks of PR were invisible. Therefore, the cationic CS is essential to tightly adsorb the negative-charged PR and GOD, which obtains a stable layer-by-layer structure. 


\section{Electrochemical behaviors of the modified electrode surface}

In this study, hydroquinone (HQ) was used as electron transfer mediator to evaluate the biocatalytic activity of GOD adsorbed on chitosan modified PR based electrode in the presence of nitrogen. The detection mechanism of glucose in this biosensor according to the following scheme $[48,49]$.

$$
\begin{gathered}
\text { Hydroquinone }(\mathrm{HQ}) \rightarrow p \text {-quinone }+2 \mathrm{H}^{+}+2 \mathrm{e}^{-} \\
\text {GOD }(\mathrm{FAD})+D \text {-glucose } \rightarrow \text { GOD }\left(\mathrm{FADH}_{2}\right)+D \text {-glucono- } \delta \text {-lactone } \\
\text { GOD }\left(\mathrm{FADH}_{2}\right)+p \text {-quinone } \rightarrow \text { GOD }(\mathrm{FAD})+\text { Hydroquinone }(\mathrm{HQ})
\end{gathered}
$$

Fig. 4 shows the CV curves with and without glucose by four different modified electrodes. The catalytic current value for the oxidation of $20 \mathrm{mM}$ glucose of the GOD/CS/PR/GCE (a), GOD/CS/GCE (b), GOD/PR/GCE (c) and GOD/GCE (d) are $66.0 \mu \mathrm{A}, 47 \mu \mathrm{A}, 6.9 \mu \mathrm{A}$ and $3.1 \mu \mathrm{A}$ at the potential of $0.6 \mathrm{~V}$ vs $\mathrm{Ag} / \mathrm{AgCl}$, respectively. In comparison to Fig. 4c and Fig. 4d, PR is useful in enhancing the biocatalytic activity of GOD on GCE surface. From Fig. 4b, the catalytic current value of GOD/CS/GCE is about 6.8 times than GOD/PR/GCE. It could be concluded that the CS has good adhesion ability and opposite charges to GOD. The best response current was obtained by GOD/CS/PR/GCE, which is 1.4 times higher than GOD/CS/GCE. We speculate the synergistic effect of CS and PR would be useful for keeping suitable orientation and enhancing the biocatalytic activity of GOD. To understand the reason of this phenomena, the following electrochemical method, QCM-D and AFM measurements were used to explain the response to glucose of adsorbed GOD on differently immobilized surfaces.

The structure and conformation of immobilized enzyme largely affect the electrocatalytic activity and electron transfer performance of enzyme-based biosensor. To obtain the electrochemical properties of the modified electrodes, we measured cyclic voltammograms (CV) of GOD/CS/PR/GCE (green), CS/PR/GCE (red), PR/GCE (blue) and bare GCE (brown) in $5 \mathrm{mM}\left[\mathrm{Fe}(\mathrm{CN})_{6}\right]^{3-4}$ containing PBS $(0.1 \mathrm{M}$, $\mathrm{pH} 5.5$ ) at a scan rate of $100 \mathrm{mV} / \mathrm{s}$ (Figure 5a). The potential difference $(\Delta E)$ between the oxidation peak and reduction peak of the CS/PR/GCE, GOD/CS/PR/GCE, bare GCE, and PR/GCE were $101 \mathrm{mV}, 171 \mathrm{mV}, 328.7 \mathrm{mV}$ and $402 \mathrm{mV}$, respectively. As compared to bare GCE and PR/GCE, the CS modified electrodes (GOD/CS/PR/GCE, 
$\mathrm{CS} / \mathrm{PR} / \mathrm{GCE}$ ) tend to facilitate the electron transfer rate.

EIS is an effective tool for evaluating the interface properties of modified electrode surface. The charge transfer resistance $\left(R_{\mathrm{ct}}\right)$ can be quantified according to the diameter of the semicircle of Nyquist plot, and is a useful parameter for evaluating the interface properties of the adsorbed protein layer on the electrode surface [50]. Fig. $5 b$ shows the Nyquist plots of PR/GCE (blue), bare GCE (brown), GOD/CS/PR/GCE (green) and CS/PR/GCE (red) obtained by using $\left[\mathrm{Fe}(\mathrm{CN})_{6}\right]^{3-/ 4-}$ as an electrochemical redox probe, respectively. The $R_{\mathrm{ct}}$ of the CS/PR/GCE, GOD/CS/PR/GCE, bare GCE, and PR/GCE modified electrodes were $75 \Omega, 240 \Omega, 570 \Omega$ and $700 \Omega$, respectively. The PR/GCE showed larger $R_{\mathrm{ct}}$ value compared with the bare GCE, which due to the semi-conductivity of pyrite. In addition, electrostatic repulsion between negatively charged PR and $\left[\mathrm{Fe}(\mathrm{CN})_{6}\right]^{3-14-}$ also may be responsible for the larger $R_{\mathrm{ct}}$. Differing from the prediction, the $R_{\mathrm{ct}}$ of CS/PR/GCE and GOD/CS/PR/GCE were smaller than those of bare GCE and PR/GCE. At $\mathrm{pH} 5.5, \mathrm{CS}\left(p K_{\mathrm{a}} \approx 10.4\right)$ exists in cationic form [51]. Thus, it can be regarded that the electrostatic binding between the cationic CS and negatively charged $\left[\mathrm{Fe}(\mathrm{CN})_{6}\right]^{3-14-}$ would accelerate the electron transfer of $\left[\mathrm{Fe}(\mathrm{CN})_{6}\right]^{3-/ 4-}$ or permeation of $\left[\mathrm{Fe}(\mathrm{CN})_{6}\right]^{3-/ 4-}$ across the adsorbed GOD/CS/PR/GCE layer, eventually leads to a smaller $R_{\mathrm{ct}}[52]$.

\section{Optimization of experimental conditions}

Since the detection process is usually affected by the dissolved oxygen, various redox active mediators (e.g., hydroquinone, hexacyanoferrate (III), p-benzoquinone, catechol, dopamine, ferrocene derivatives) were used to replace molecular oxygen as the electron acceptor of GOD, which could eliminate the interference of dissolve oxygen for the second generation GOD biosensors. Here, four mediators including hydroquinone (HQ), ferrocene (FC), catechol (CC), and dopamine (DA) were selected and compared in this research. As shown in Fig. 6a, the performance of HQ is the best among the selected mediators. Therefore, HQ was chosen as the mediators in subsequent experiments.

Fig. $6 \mathrm{~b}$ is the optimization of PR concentration for the detection of $20 \mathrm{mM}$ glucose by $\mathrm{CV}$ measurement. The response current toward glucose increases in the concentration range from 20 to $40 \mathrm{mg} / \mathrm{mL}$ and reaches a maximum value at $40 \mathrm{mg} / \mathrm{mL}$ 
of pyrite. Thus, $40 \mathrm{mg} / \mathrm{mL}$ was chosen as the optimal PR concentration for the following experiment. The influence of the chitosan concentration range from $0.02 \%$ to $0.3 \%(\mathrm{v} / \mathrm{v} \%)$ on the peak current response also investigated, which shown in Fig. $6 \mathrm{c}$. The current response of the GOD/CS/PR/GCE reaches the highest value when the concentration of chitosan is $0.05 \%$. Certain amounts of CS is essential to keep the adhesion ability of GOD on the PR surface. However, higher concentration of chitosan would hinder the electron transfer rate of immobilized GOD. Therefore, $0.05 \%$ of chitosan was used in the following experiments.

A series of GOD concentrations including 1.0, 1.5, 2.0, 2.5, 3.0, $3.5 \mathrm{mg} / \mathrm{mL}$ were optimized to obtain the best electrochemical performance of GOD/CS/PR/GCE as shown in Fig. 6d. When the GOD concentration is higher than $2 \mathrm{mg} / \mathrm{mL}$, the current response decreased severely. Therefore, $2 \mathrm{mg} / \mathrm{mL}$ glucose oxidase was selected in this experiment. The adsorption $\mathrm{pH}$ is important for immobilized enzymes. The effect of the adsorption $\mathrm{pH}$ of GOD on the $\mathrm{CV}$ response to glucose was also investigated over a $\mathrm{pH}$ range from 4.5 to 8.0 using $0.1 \mathrm{M}$ PBS (Fig. 6e). The maximum current response obtained at a $\mathrm{pH}$ of 5.5, which is in accordance with the optimal pH of GOD [33]. In addition, the electrolyte $\mathrm{pH}$ showed not so much different from the $\mathrm{pH}$ range of 4.5 to 6.5. And the maximum peak current value is also 5.5. At pH 5.5, PR, CS and GOD are negatively charged, positively charged and negatively charged, respectively. The three layers of PR, CS and GOD were tightly adsorbed through electrostatic force. Furthermore, a maximum protein adsorption is often found at a $\mathrm{pH}$ value close to $\mathrm{pI}$ of the protein, due to reduced electrostatic repulsion of neighboring proteins [53].

Adsorption Behavior of GOD Evaluated by Quartz Crystal Microbalance with Dissipation (QCM-D).

QCM-D is a very sensitive instrument for measuring the mass changes of adsorption species in the change of resonance frequency, $\Delta F$, and for obtaining the information of viscoelasticity in the change of dissipation factor, $\Delta D$. [54, 55]. The surface mass change of quartz crystal oscillator was converted to frequency change of the output electrical signal, which is used to characterize the mass change and thickness of the adsorbed proteins. In addition, the conformational change of proteins 
and the hydration level of the biomolecule films could also be evaluated by QCM-D [53].

To understand the adsorption mechanisms, we studied the role of CS on the adsorption of GOD with the use of QCM-D equipped with a pure $\mathrm{FeS}_{2}$ sensor tip. Fig. 7a showed the QCM-D results of step by step adsorption of CS and GOD on FeS 2 tip $\left(\mathrm{GOD} / \mathrm{CS} / \mathrm{FeS}_{2}\right)$. Fig. $7 b$ was the GOD alone adsorption on $\mathrm{FeS}_{2}$ tip $\left(\mathrm{GOD} / \mathrm{FeS}_{2}\right)$. The first decrease in frequency in Fig. 7a was related to the adsorption of chitosan on the $\mathrm{FeS}_{2}$ sensor tip. The net $\Delta F$ gradually increased to ca. $50 \mathrm{~Hz}$, which corresponds to the mass of the adsorbed CS. The frequency further decreased from $-50 \mathrm{~Hz}$ to $-230 \mathrm{~Hz}$ (net $\Delta F, 180 \mathrm{~Hz}$ ) when GOD was injected to the system at $1500 \mathrm{~s}$, illustrating that a large amount of GOD was adsorbed on the surface of CS. The adsorbed GOD was very stable on $\mathrm{CS}$ modified $\mathrm{FeS}_{2}$ tip even added distilled water (DW) in detecting system except a temporary increase which caused by the adsorption of water. And the frequency decreases again due to the instability of the associated water. Fig. $7 \mathrm{~b}$ showed the net $\Delta F$ was about $75 \mathrm{~Hz}$ when GOD adsorption alone. The adsorbed GOD amount of $\mathrm{GOD} / \mathrm{CS} / \mathrm{FeS}_{2}$ is about 2.4 times larger than that of $\mathrm{GOD} / \mathrm{FeS}_{2}$. In addition, the adsorbed GOD is very weak, and easily detached from $\mathrm{FeS}_{2}$ sensor surface when DW was added. These results indicate that the presence of pre-adsorbed chitosan enhances the adsorbed amount of GOD.

The change of dissipation reveals the information about the viscoelasticity and morphology of the $\mathrm{FeS}_{2}$ sensor and is used as a method to measure the substrate thickness, hydration state and conformation [56]. The first rapid increase in dissipation $(\Delta D \approx 19 \mathrm{ppm})$ demonstrates that the adsorption of CS causes the thickness of the substrate. Subsequently, the continued increase of dissipation result $(\Delta D \approx 15 \mathrm{ppm}$ ) was caused by the further addition of GOD. However, the final $\Delta D$ value of GOD adsorbed alone $\left(\mathrm{GOD} / \mathrm{FeS}_{2}\right)$ is $0 \mathrm{ppm}$, which reflect the quick (rapid) detachment of GOD from $\mathrm{FeS}_{2}$ sensor surface. These results are in accordance with the $\mathrm{CV}$ data in Fig. 4. Furthermore, the $\Delta D / \Delta F$ value for the GOD/CS/FeS 2 layer was $82 \times 10^{-9}$. A smaller $\Delta D / \Delta F$ value for the absorbed layer suggests that $\mathrm{CS}$ and GOD more rigidly attached to $\mathrm{PR}\left(\mathrm{FeS}_{2}\right)[51]$.

A possible explanation for this result could be assessed with the role of isoelectric point. The isoelectric point of bare $\mathrm{PR}$ is about $\mathrm{pH} 3$ [57]. When the $\mathrm{pH}$ value is greater than 3, the surface of PR is negatively charged. The isoelectric point 
of CS is 6.3 [51]. When the $\mathrm{pH}$ value below 6.3, chitosan has a positive charge due to protonation of amino groups. Electrostatic effect is useful to stable the interaction of CS and PR in the first step. In addition, the isoelectric point of GOD is 4.2 [58]. Therefore, GOD is also negatively charged in pH 5.5, which tightly adsorbed on positively charged CS surface. These results predict that CS worked as a double-face glue to adhere PR and GOD. Thus, the GOD on the surface of PR is not stable due to the electrostatic repulsion effect.

AFM images with the height profiles of PR/GCE (Fig. 8a), GOD/CS/PR/GCE (Fig. 8b) and GOD/PR/GCE (Fig. 8c) were evaluated. The heights of GOD/CS/PR/GCE (106 nm) and GOD/PR/GCE (102 nm) are increased in comparison to PR/GCE (95 nm). There are not so much height differences among the three electrodes because of the heterogeneous property of PR and the tightly adsorbed layers of PR, CS and GOD. The modification of GOD would cover the CS/PR/GCE surface completely as seen from the rugged, uneven and hill-like image morphology. And this result is also in accordance with the SEM and XRD (data not shown) measurements.

\section{Electrochemical performances of GOD/CS/PR/GCE biosensor}

The CVs of GOD/CS/PR/GCE with and without glucose in $0.1 \mathrm{M}$ phosphate solution ( $\mathrm{pH}$ 5.5) containing $5 \mathrm{mM}$ HQ under the nitrogen atmosphere are shown in Fig. 9. The inset graph reflects the relativity between the glucose concentrations in the electrolyte and the catalytic currents. The catalytic current increased with increasing the concentration of glucose, indicating the GOD/CS/PR/GCE biosensor has a good linear relationship to glucose in the range of $0.5-60 \mathrm{mM}$, with a regression equation of $I=0.897 c-0.3016$ and a correlation coefficient of 0.9996 . The detection limit (LOD) was $50 \mu \mathrm{M}$. Table 2 summarizes the compared characteristics of the reported GOD-based glucose biosensors. Although the LOD of this sensor is not superior with other synthesized nanomaterial-based systems, this biosensor shows acceptable linear range, especially consideration the raw mineral was used as support electrode.

\section{Lifetime of the GOD/CS/PR/GCE biosensor}


Lifetime of the same GOD/CS/PR/GCE biosensor was evaluated by using CV method toward the detection of $20 \mathrm{mM}$ glucose. Fig. 10 shows the peak current response which was checked at $2 \mathrm{~h}, 4 \mathrm{~h}, 24 \mathrm{~h}, 48 \mathrm{~h}$ and $72 \mathrm{~h}$, respectively. It was found that the biosensor lost $1.7 \%$ of the initial response at $4 \mathrm{~h}, 2.3 \%$ at $24 \mathrm{~h}, 5.8 \%$ at $48 \mathrm{~h}$, and $6.9 \%$ at $72 \mathrm{~h}$. This glucose biosensor is stored in a refrigerator at $4{ }^{\circ} \mathrm{C}$ in dry state when not in use. The results show that the electrode has good long-term stability.

\section{Conclusions}

In this study, a simple sandwich structure of GOD/CS/PR/GCE biosensor was fabricated to detect glucose through layer-by-layer electrostatic force. CS worked as a double-face glue to stabilize the GOD on the PR modified surface. The surface morphology, adsorption mechanism and electrochemical behaviors were examined by CV, EIS, QCM-D, SEM and AFM instruments. If this strategy can be adopted to other sulfide minerals and enzymes, then this physical adsorption-based multilayer structure would be expected to be one of the versatile tools to develop various bioelectronics devices.

\section{Disclosure statement}

On behalf of all authors, the corresponding author states that there is no conflict of interest.

\section{Acknowledgements}

The authors are gratefully acknowledge the financial support from the University of Science and Technology, Liaoning (No. 2019TD01 and No. 2020QN09).

\section{Reference}


1. A. Samphao, P. Butmee, J. Jitcharoen, L. Švorc, G. Raber, K. Kalcher, Talanta., 2015, 42, 35-42.

2. N. H. Cho, J. E. Shaw, S. Karuranga, Y. Huang, J. D. Rocha Fernandes, A.W. Ohlrogge, B. Malanda, Diabetes. Res. Clin. Pract., 2018, 138, 271-281.

3. N. I. Chandrasekaran, M. Manickam, Sens. Actuat. B Chem., 2019, 288, 188-194.

4. E. B. Bahadir, M. K. Sezginturk, Anal. Biochem., 2015, 478, 107-120.

5. X. H. Yuan, J. H. Wang, K. Xia, Adv. Funct. Mater., 2005, 15, 803-809.

6. M. R. H. Nezhad, J. Tashkhourian, J. Khodaveisi, J. Iran. Chem. Soc., 2010, 7, S83-S91.

7. L. Li, X. Cai, Y. Ding, S. Gu, Q. Zhang, Anal. Methods, 2013, 5, 6748-6754.

8. N. V. Klassen, D. Marchington, C. E. McGowan, Anal. Chem., 1994, 66, 2921-2925. .

9. N. Li, J. Z. Guo, B. Liu, H. Cui, L. Q. Mao, Y. Q. Lin, Anal. Chim. Acta, 2009, 645, 48-55.

10. W. Cai, T. Lai, H. Du, J. Ye, Sens. Actuat. B Chem., 2014, 193, 492-500.

11. M. Ahn, J. Kim, J. Electroanal. Chem., 2012, 683, 75-79.

12. D. P. Li, X. Y. Liu, R. Yi, J. X. Zhang, Z. Q. Su, G. Wei, Inorg. Chem. Front, 2018, 5, 112-119.

13. S. Su, H. F. Sun, F. Xu, L.H. Yuwen, L. Wang, Electroanalysis, 2013, 25, 2523-2529.

14. I. K. Deshapriya, C. V. Kumar, Langmuir, 2013, 29, 4001-14016.

15. D. Ragupathy, A. I. G. K. P. Lee, Microchim. Acta, 2009, 166, 303-310.

16. R. S. Dey, C. R. Raj, J. Phys. Chem. C., 2010, 114, $21427-21433$.

17. B. B.G. Choi, H. Park, T. J. Park, M.H. Yang, J.S. Kim, S.Y. Jang, N.S. Heo, S.Y. Lee, J. Kong, W. H. Hong, ACS Nano, 2010, 4, 2910-2918.

18. C. Shan, H. Yang, J. Song, D. Han, A. Ivaska, L. Niu, Anal. Chem., 2009, 81, 2378-2382.

19. F. Doroftei, T. Pinteala, A. Arvinte, Microchim. Acta, 2013, 181, 111-120.

20. V. S. Joshi, J. Kreth, D. Koley, Anal. Chem., 2017, 89, 7709-7718.

21. K. Thenmozhi, S. Sriman Narayanan, Anal. Bioanal. Chem., 2006, 387, 1075-1082.

22. D. R. Shankaran, N. Uehera, T. Kato, Anal. Bioanal. Chem., 2002, 374, 412-415.

23. R. Zhao, Y. Wang, Z. Zhang, Y. Hasebe, D. Tao, Anal. Sci., 2019, 35, 733-738.

24. R. Zhao, Y. Wang, Int. J. Electrochem. Sci., 2020, 15, 1595-1605.

25. N. Rohaizad, C. C. Mayorga-Martinez, Z. Sofer, M. Pumera, ACS Appl. Mater. Interfaces, 2017, 9, 40697-40706.

26. X. Cao, Microchim. Acta, 2014, 181, 133-1141.

27. H. Huang, J. Zhang, M. Cheng, K. Liu, X. Wang, Microchim. Acta, 2017, 184, 4803-4808.

28. R. A. Guidotti, P. J. Masset, J. Power. Sources, 2008, 183, 388-398.

29. Y. Huai, C. Plackowski, Y. Peng, Miner. Eng., 2017, 111, 131-139. 
30. A. P. Chandra, A. R. Gerson, Surf. Sci. Rep., 2010, 65, 293-315.

31. Y. Wang, K. J. Zhao, D. P. Tao, F. G. Zhai, H. B. Yang, Z. Q. Zhang, RSC Adv., 2018, 8, 5013-5019.

32. X.C. Tan, Y. X. Tian, P. X. Cai, X.Y. Zou, Anal. Bioanal. Chem., 2005, 381, 500-507.

33. Y. Wang, Y. Hasebe, J. Electrochem. Soc., 2012, 159, F110-F118.

34. M. A. Arnold, G. A, Rechnitz, Anal. Chem., 1982, 54, 2315-2317.

35. Y. Ikariyama, S. Yamauchi, T. Yukiashi, H. Ushioda, Anal. Lett., 1987, 20, 1791-01801.

36. T. Yao, Anal. Chim. Acta, 1983, 148, 27-33.

37. G. J. Moody, G. S. Sanghera, J. D. R. Thomas, Analyst, 1986, 111, 605-609.

38. B. F. Y. Yon Hin, C. R. Lowe, Anal. Chem., 1987, 59, 2111-2115.

39. J. X. Jing, Y. C. Hong, Anal. Biochem., 2000, 280, 221-226.

40. N. C. Foulds, C. R. Lowe, J. Chem. Soc., Faraday Trans. 1, 1986, 82, 1259-1624.

41. J. Okuda, J. Wakai, N. Yuhashi, K. Sode, Biosens. Bioelectron., 2003, 18, 699-704.

42. Y. Fang, R. Zhang, B. Duan, M. Liu, A. Lu, L. Zhang, ACS Sustainable Chem. Eng., 2017, 5, 2725-2733.

43. K. Zhu, J. Duan, J. Guo, S. Wu, A. Lu, L, Zhang, Biomacromolecules, 2017, 18, 3904-3912.

44. Decher G, Science, 1997, 277, 1232-1237.

45. K. Ariga, M. Onda, Y. Lvov, T. Kunitake, Chem. Lett., 1997, 26, 25-26.

46. Q. Xu, S. X. Gu, L. Jin, Y. E. Zhou, Z. Yang, W. Wang, X. Hu, Sens. Actuators B Chem., 2014, 190, 562-569.

47. C. V. Kumar, A. Chaudhari, J. Am. Chem. Soc., 2000, 122, 830-837.

48. Y, Wang, Y. Hasebe, J. Electrochem. Soc., 2012, 159, F110-F118.

49. R. Zhao, Y. Wang, Y. Hasebe, Z. Zhang, D. Tao, Int. J. Electrochem. Sci., 2020, 15, 1595-1605.

50. Q. Chi, J. Zhang, J. U. Nielsen, E. P. Friis, I. Chorkendorff, G. W. Canters, J. E. T. Andersen, J. Ulstrup, J. Am. Chem. Soc., 2000, 122, 4047-4055.

51. P. Sorlier, A. Denuzière, C. Viton, A. Domard, Biomacromolecules, 2001, 2, 765-772.

52. Y. Zhang, Y. Wang, Z. Zhang, A. Sobhy, S. Sato, M. Uchida, Y. Hasebe, ACS Omega, 2021, 21, 13719-13727.

53. A. G. Hemmersam, K. Rechendorff, F. Besenbacher, B. Kasemo, D. S. Sutherland, J. Phys. Chem. C., 2008, 112, 4180-4186.

54. G. Hu, J. A. Heitmann Jr, O. J. Rojas, J. Phys. Chem B., 2009, 113, 14761-14768.

55. S. A. Maurer, C.N. Bedbrook, C.J. Radke, Langmuir, 2012, 28, 14598-14608.

56. A. Kumagai, S.H. Lee, T. Endo, Biomacromolecules, 2013, 14, 2420-2426.

57. W. Zhang, W. Sun, Y. Hu, J. Cao, Z. Gao, Minerals, 2019, 9,549.

58. B. E. Swoboda, V. Massey, J. Biol. Chem.2 1965, 240, 2209-2215. 
59. X. Jiang, Y. Wu, X. Mao, X. Cui, L. Zhu, Sens. Actuat. B Chem., 2011, 153, 158-163.

60. J. Yu, J. Tu, F. Zhao, B. Zeng, J. Solid State Electrochem., 2010, 14, 1595-1600.

61. M. Zhou, L. Shang, B. Li, L. Huang, S. Dong, Biosens. Bioelectron., 2008, 24, 442-447.

62. O. Parlak, A. İncel, L. Uzun, A. P. F. Turner, A. Tiwari, Biosens. Bioelectron., 2017, 89, 545-550.

63. E. Ghasemi, E. Shams, N. Farzin Nejad, J. Electroanal. Chem., 2015, 752, 60-67.

64. S. Wu, Z. Zeng, Q. He, Z. Wang, S. J. Wang, Y. Du, Z. Yin, X. Sun, W. Chen, H. Zhang, Small, 2012, 8, 2264-2270. 
Table 1. XRD analysis of pure $\mathrm{FeS}_{2}$ and natural pyrite

\begin{tabular}{ccc}
\hline Materials & $\mathrm{FeS}_{2}$ & Other impurities \\
\hline $\mathrm{FeS}_{2}$ & $99.5 \%$ & $0.5 \%$ \\
pyrite & $78.8 \%$ & $21.2 \%$ \\
\hline
\end{tabular}


Table 2. Comparison of GOD based electrochemical glucose biosensors

\begin{tabular}{lllll}
\hline Electrode & Technique & $\begin{array}{l}\text { Linear } \\
\text { range } \\
(\mathrm{mM})\end{array}$ & $\begin{array}{l}\text { Detection } \\
\text { limit } \\
(\mu \mathrm{M})\end{array}$ & Reference \\
\hline GOD/Pt/MOC/Au & Amperometry & $0.05-3.7$ & 50 & {$[59]$} \\
GOD-mesoFe/C-Nafion/Pt & Amperometry & $0.2-10$ & 80 & {$[60]$} \\
Nafion/GOD/OMC/GCE & Amperometry & $0.5-15$ & 156 & {$[61]$} \\
GOD/AuNPs-MoS $/ \mathrm{Au}$ & $\begin{array}{l}\text { Chronoamperome } \\
\text { try }\end{array}$ & $0.25-13.2$ & 0.042 & {$[62]$} \\
GOD/TCT/AP/OMC/GCE & DPV & $0.1-1$ & 38 & {$[63]$} \\
GOD/rMoS $/ \mathrm{CS} / \mathrm{APTES} /$ & Voltammetry & $3-20$ & - & {$[64]$} \\
GCE & Voltammetry & $0.5-60$ & 50 & This study \\
GOD/CS/FeS $/ \mathrm{GCE}$ & &
\end{tabular}

Pt: Platinum; MOC: Mesoporous carbon; GOD: Glucose oxidase; GCE: Glassy carbon electrode; mesoFe/C: Magnetic iron oxide mesoporous carbon; $\mathrm{rMoS}_{2}$, reduced $\mathrm{MoS}_{2}$; AuNPs, Au nanoparticles; TCT: 2,4,6-Trichloro-1,3,5-triazine, AP: Aminophenyl; APTES, 3-aminopropyltriethoxysilane 


\section{Figure Captions}

Fig. 1 Preparation of GOD/CS/PR/GCE biosensor.

Fig. 2 XRD patterns of pure $\mathrm{FeS}_{2}$ (a) and natural pyrite (b).

Fig. 3 The SEM images of (a) PR/GCE, (b) GOD/PR/GCE, (c) CS/PR/GCE and (d) GOD/CS/PR/GCE.

Fig. 4 Cyclic voltammograms of the GOD/CS/PR/GCE (a), GOD/CS/GCE (b), GOD/PR/GCE (c), GOD/GCE (d) in $\mathrm{N}_{2}$-saturated 0.1 M PBS (pH5.5) containing $5 \mathrm{mM}$ HQ with (red) and without glucose (black). The potential scan rate is 5 $\mathrm{mV} / \mathrm{s}$, and the starting potential is $-0.4 \mathrm{~V}$ vs $\mathrm{Ag} / \mathrm{AgCl}$.

Fig. 5 CVs (a )and EIS (b)Nyquist plots of the PR/GCE (blue), bare GCE (brown), GOD/CS/PR/GCE (green) and CS/PR/GCE (red), The electrolyte is $\mathrm{N}_{2}$-saturated $0.1 \mathrm{M}$ PBS ( $\mathrm{pH} 5.5)$ containing $5 \mathrm{mM}\left[\mathrm{Fe}(\mathrm{CN})_{6}\right]^{3-/ 4-}$. The potential was set to the formal potential of the $\left[\mathrm{Fe}(\mathrm{CN})_{6}\right]^{3-/ 4-}$ redox system. The amplitude is $0.005 \mathrm{~V}$. The frequency is from $0.1 \mathrm{~Hz}$ to $10 \mathrm{kHz}$. Concentrations of each species in adsorption solution: $[\mathrm{PR}]=40 \mathrm{mg} / \mathrm{mL}$ (dispersion); $[\mathrm{GOD}]=2 \mathrm{mg} / \mathrm{mL} ;[\mathrm{CS}]=0.05 \%$ $(\mathrm{v} / \mathrm{v} \%)$.

Fig. 6 Effect of mediators (a), PR concentration (b), CS concentration (\%) (c), GOD concentration (d), GOD adsorption $\mathrm{pH}(\mathrm{e})$, and electrolyte $\mathrm{pH}$ (f) on the catalytic current response for $20 \mathrm{mM}$ glucose. [PR] = $40 \mathrm{mg} / \mathrm{mL}$ (for panels a, c-f); $[C S]=0.05 \%(\mathrm{v} / \mathrm{v} \%)$ (for panels a-b, and d-f); [GOD] $=2 \mathrm{mg} / \mathrm{mL}$ (for panels a-c, e-f); electrolyte $\mathrm{pH}=5.5$ (for panels a-e).

Fig. 7 QCM-D responses for the step-by-step adsorption of GOD/CS/FeS 2 (a), $\mathrm{GOD} / \mathrm{FeS}_{2}$ (b) on the $\mathrm{FeS}_{2}$ tips in $0.1 \mathrm{M}$ PBS (pH 5.5). Changes in frequency and dissipation at $15 \mathrm{MHz}$. The experiment was conducted at $25{ }^{\circ} \mathrm{C}$ ([GOD] $=2$ $\mathrm{mg} / \mathrm{mL} ;[\mathrm{CS}]=0.05 \%$ ). The carrier and sample flow rate were $100 \mu \mathrm{L} / \mathrm{min}$.

Fig. 8 AFM images of the PR/GCE (a), GOD/CS/PR/GCE (b) and GOD/PR/GCE (c).

Fig. $9 \mathrm{CV}$ curves of GOD/CS/PR/GCE with different concentrations of glucose in a $0.1 \mathrm{M}$ phosphate solution ( $\mathrm{pH} 5.5$ ) containing $5 \mathrm{mM}$ HQ in $\mathrm{N}_{2}$ atmosphere. The potential scan rate was $5 \mathrm{mV} / \mathrm{s}$ with a starting potential of $-0.4 \mathrm{~V}$. 
Fig. 10 Long-term stability of the electrode. 


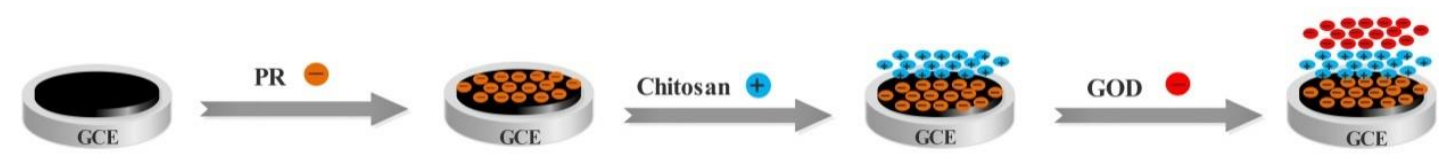

Fig. 1 

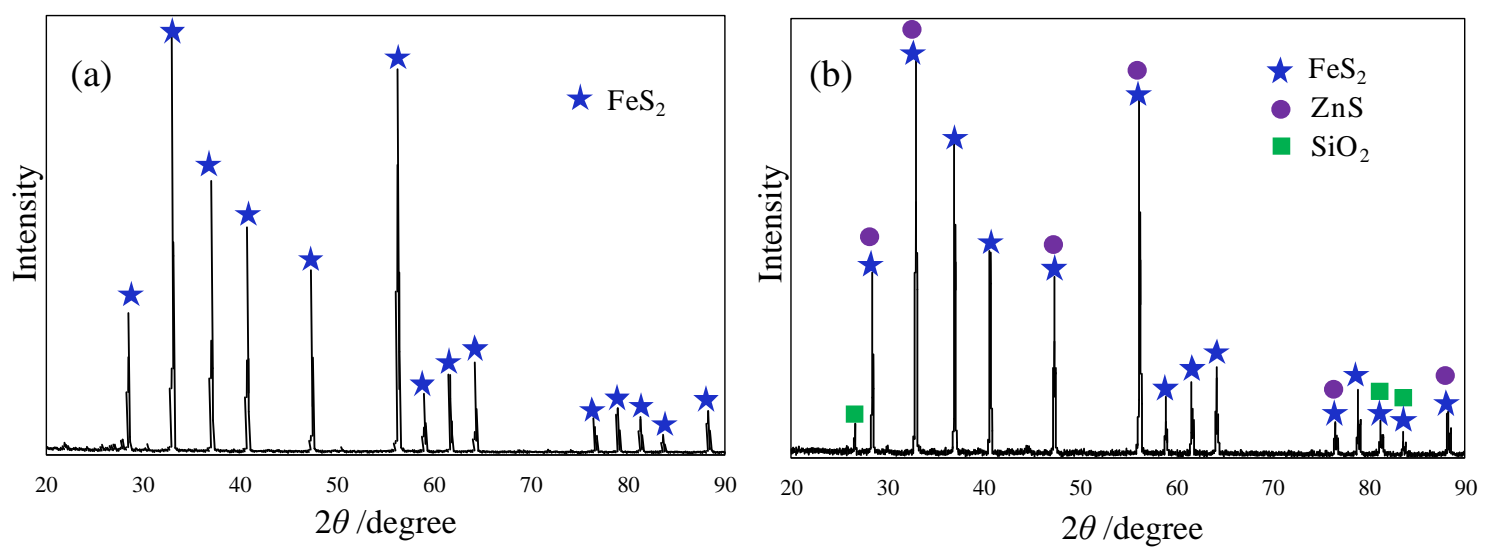

Fig. 2 

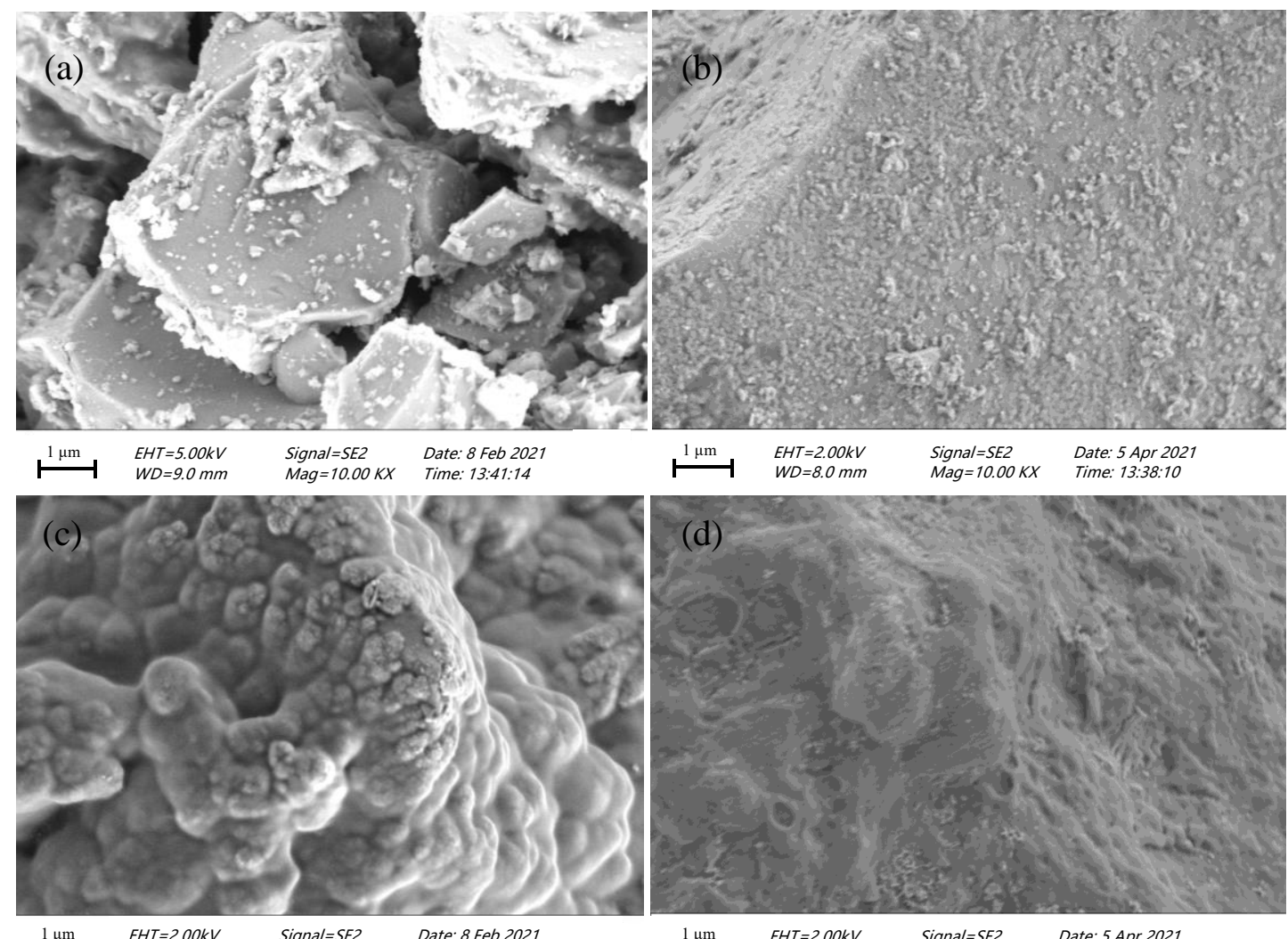

$\begin{array}{llll}1 \mu \mathrm{m} & \begin{array}{ll}E H T=2.00 \mathrm{kV} \\ W D=10.6 \mathrm{~mm}\end{array} & \begin{array}{l}\text { Signal }=S E 2 \\ \text { Mag }=10.00 \mathrm{KX}\end{array} & \text { Date: } 8 \text { Feb } 2021 \\ & \text { Time: } 14: 32: 52\end{array}$

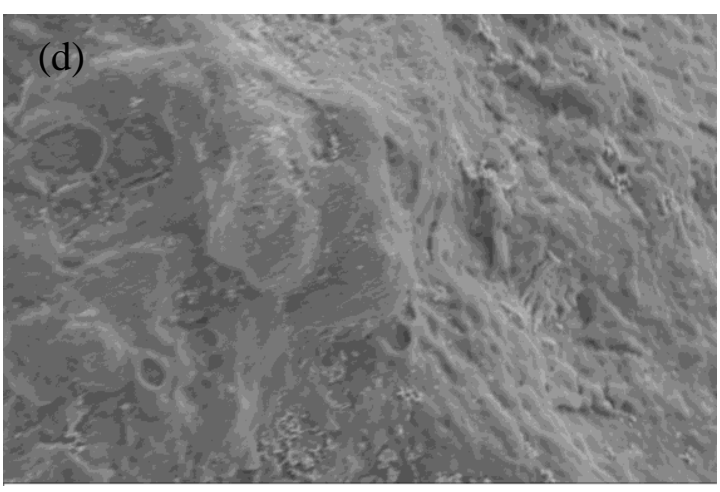

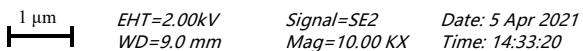

Fig. 3 


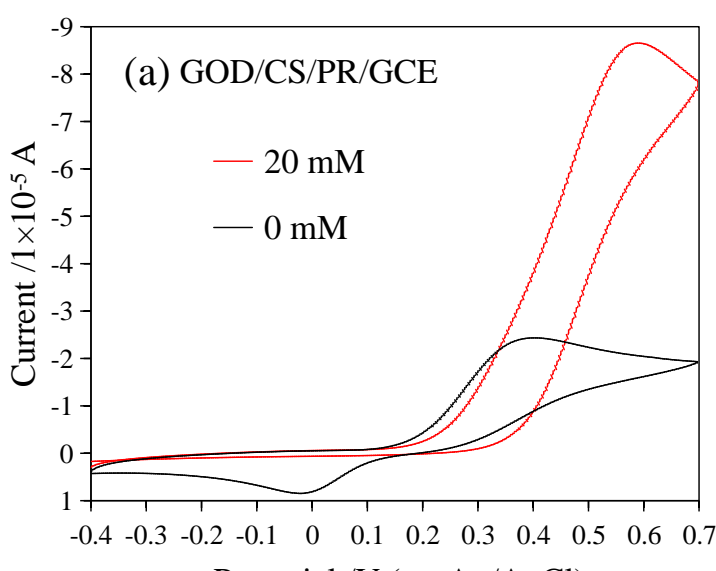

Potential /V (vs. $\mathrm{Ag} / \mathrm{AgCl}$ )

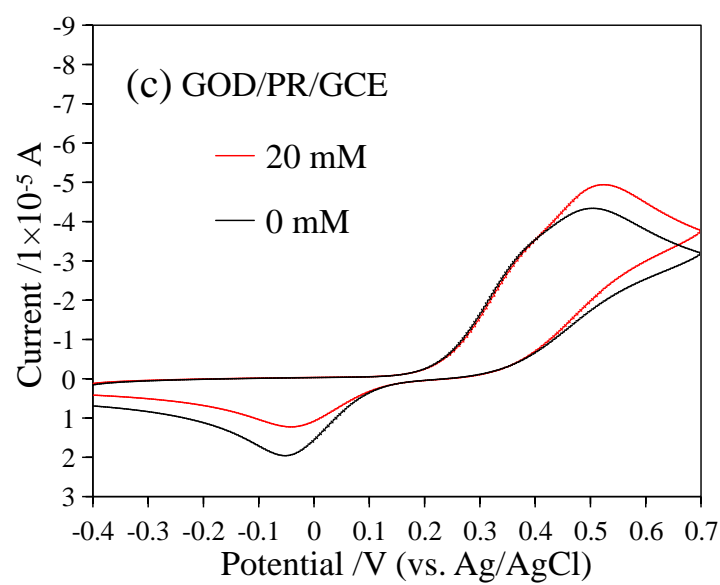

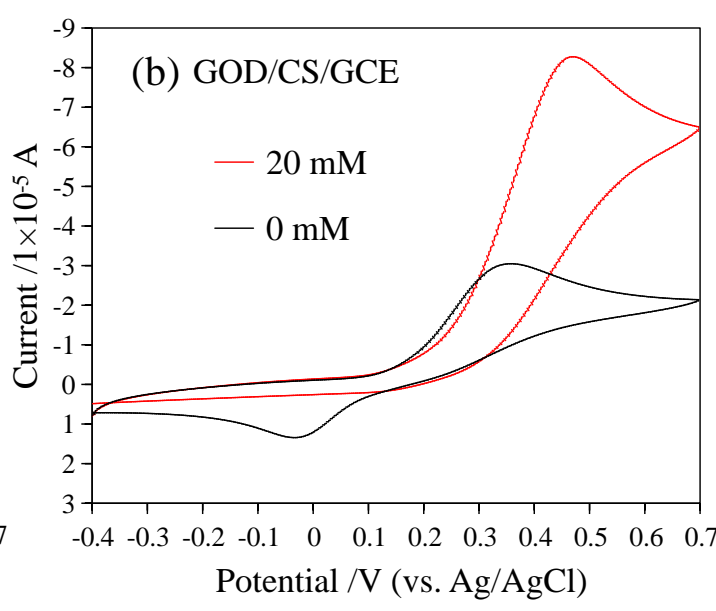

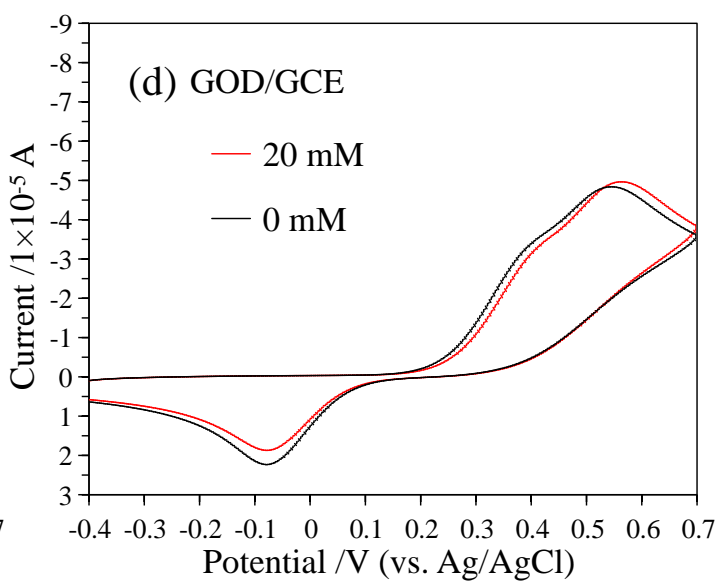

Fig. 4 

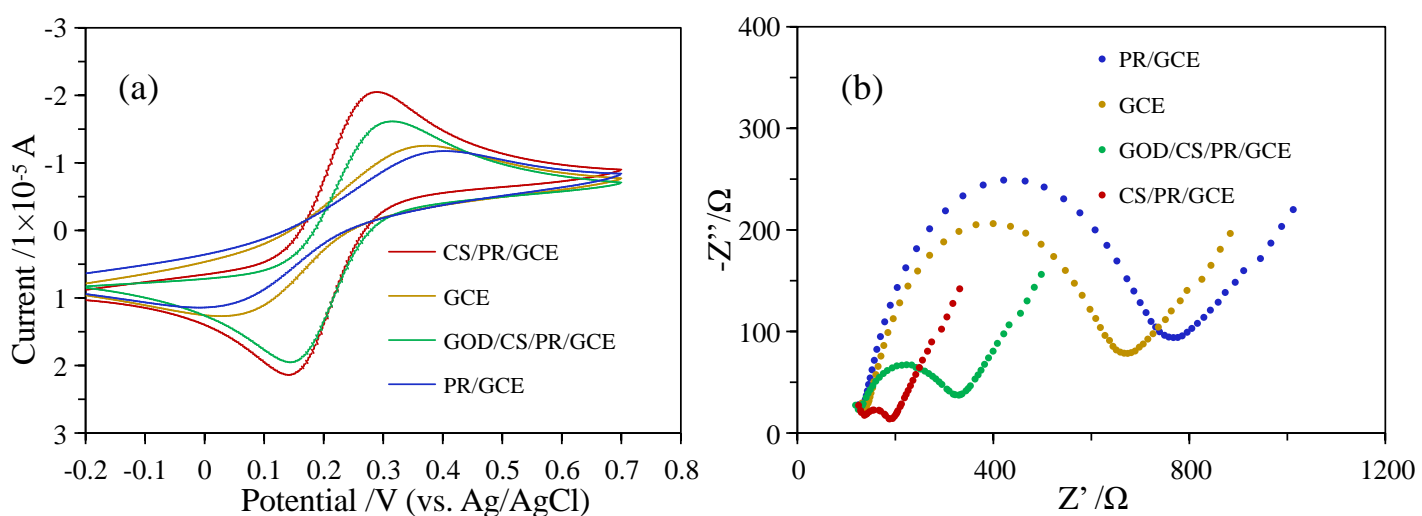

Fig. 5 

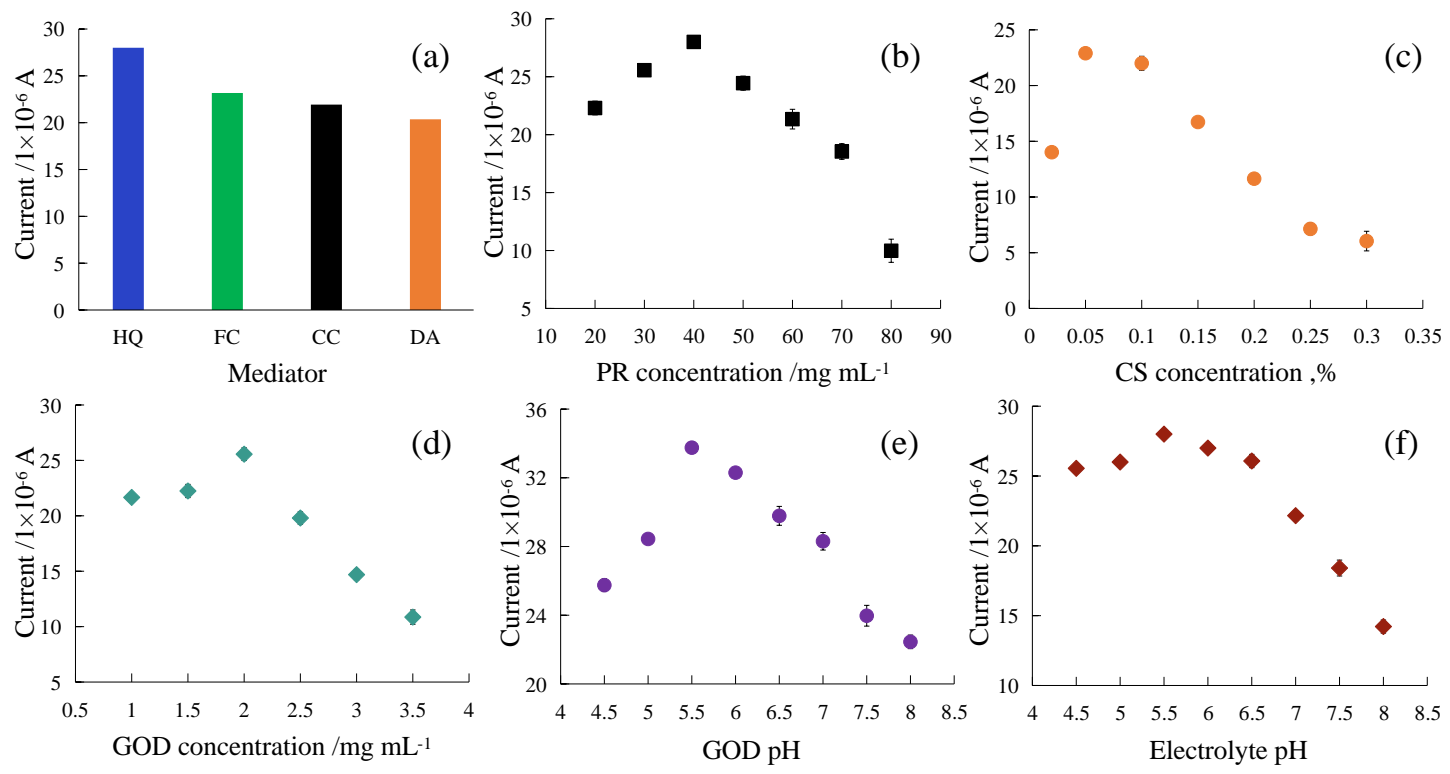

Fig. 6 


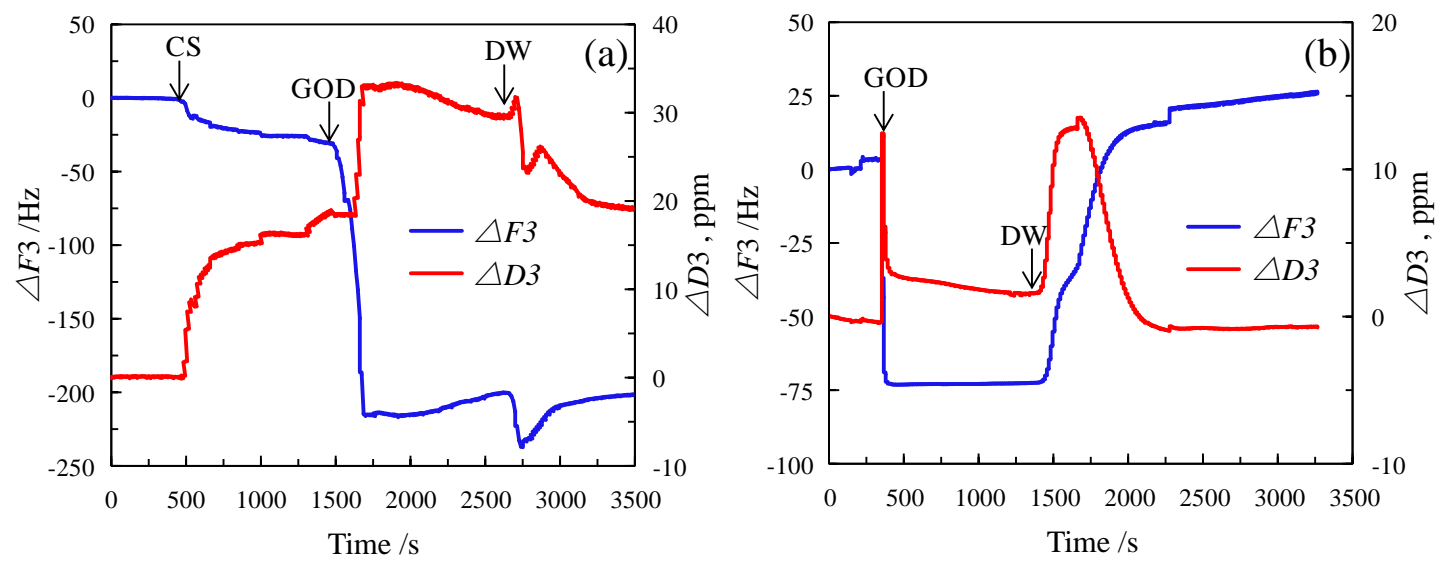

Fig. 7 


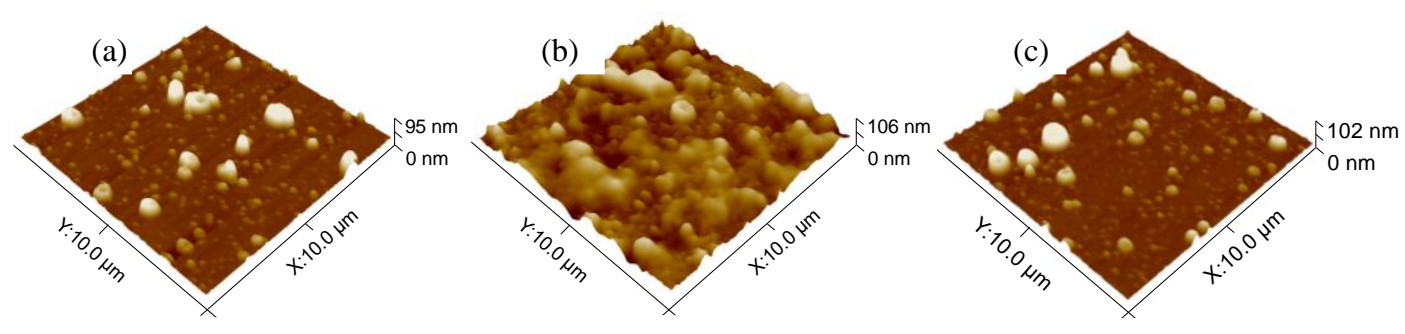

Fig. 8 


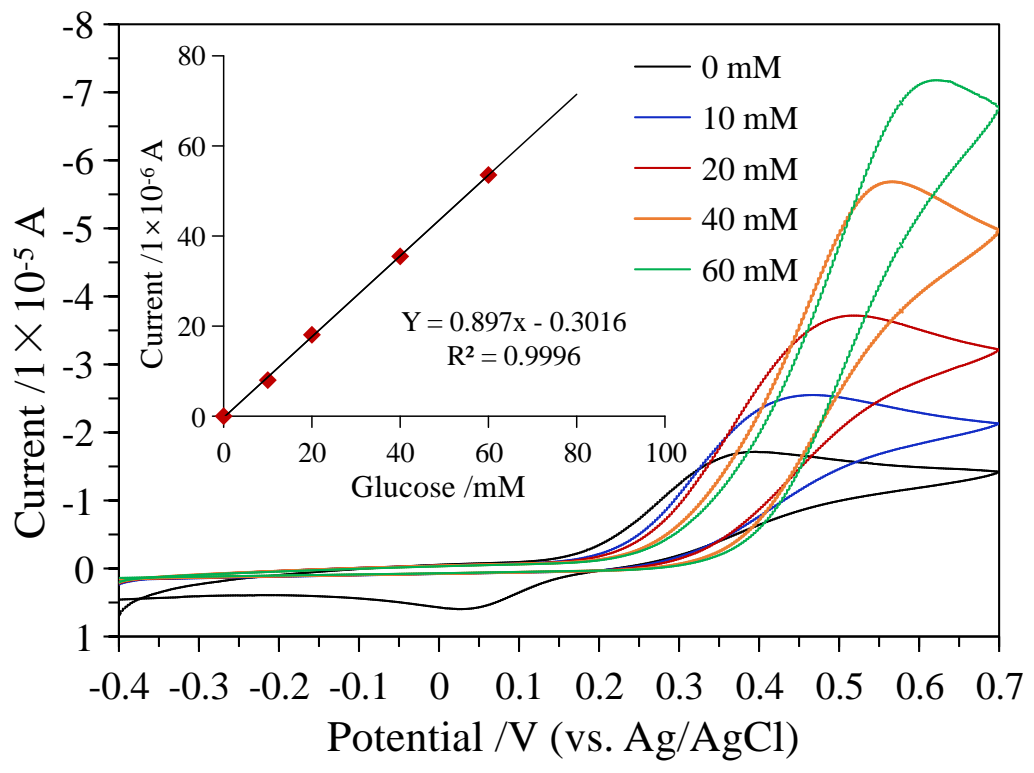

Fig. 9 


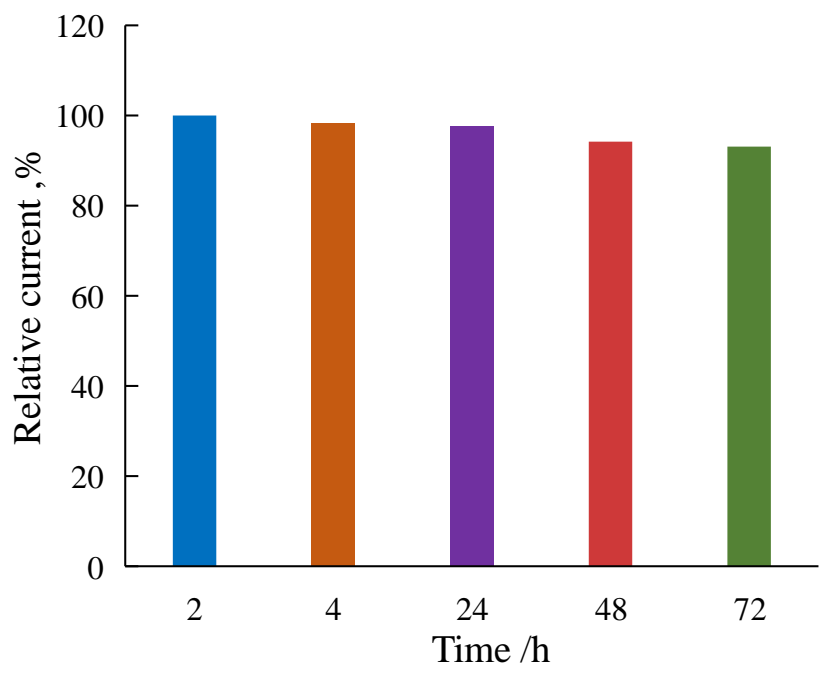

Fig. 10 


\section{Graphical Index}

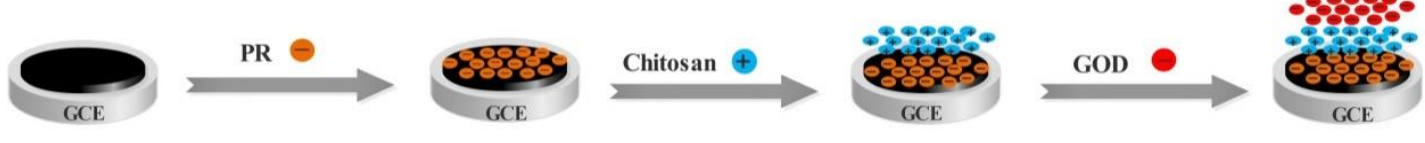

